\title{
CONCURSO DE ENSAYOS: TENDIENDO PUENTES 2016 FRANCISCO, POLÍTICA Y SOLIDARIDAD
}

Ricardo A. Rubio Morales

Estudiante de Administración en la UMCH

Algunos años atrás, cuando caminaba por las calles del Centro de Lima, me topé con un vagabundo que parecía estar medio loco por la forma cómo vestía. Andaba gritando por las calles su inmenso amor por Dios. En ese momento me quedé mudo, no podía creer lo que veía. Le gritaba al mundo, a sus hermanos, que se amaran y que no se dejaran llevar por el supuesto "dios dinero". Me acerqué para escuchar más lo que decía: "Algún día todos tendrán que morir, dejarán este mundo plagado placeres y de injusticas, y no se llevarán ni sus autos, ni sus lujos, ni sus joyas; tal vez muera mañana, tal vez ustedes lo hagan también, es hora de arrepentirse y regresar con Dios, porque él los ama de verdad y siempre estará dispuesto a perdonarnos".

Ese día, aquel vagabundo alzó su voz por muchos, aquellos que son explotados, aquellos que mueren de hambre, aquellos que sufren en silencio en este mundo lleno de dolor y angustia, aquellos que ya no tienen ni fuerza para llorar. Gritaba al mundo un cambio, nos invitaba a ser parte de ello, nos invitaba a ser compasivos y solidarios, pero nadie lo escuchaba... solo lo ignoraban y seguían caminado. Los verdaderos locos aquel día fuimos nosotros, los que pasamos frente a él, lo escuchamos y sabiendo que tenía razón, no hicimos nada. Ese día callamos las injusticas que vive nuestra sociedad.

Lo que más me duele al recordar aquel suceso, es que en aquel entonces estaba totalmente desequilibrado, pues vi a muchos de mis hermanos sufrir por hambre, por frio, vi a muchos apuñalarse entre sí por dinero, me alejé de todos ellos, dejé que muriesen, los dejé sufrir solos, iY solo seguía caminado!, no quería ver ni oír, estaba bien y eso fue lo único que me importó.

Aquel día frente al altar de Dios, caí de rodillas y comencé a llorar, lloré por todo lo que callé, por negarme a estar con él, por aprovecharme de los demás. En aquel momento en mi cabeza solo aparecieron personas que sufrían por hambre, los explotados, sentí tanto dolor, que creo que nunca podré olvidarlo. Ese día lloré 
por mis hermanos que sufrían, y en mi interior me preguntaba cómo era posible de que Dios pudiese soportar ver a sus hijos sufrir, llorar sangre, no lo entendía, estaba adolorido, como era posible que no hiciera nada. Si ellos lloran tu nombre finalmente le reclame - iPorque no haces algo! De repente en un instante lo entendí, no sé cómo llegué ahí, pero estaba frente a él arrepentido, buscando respuestas para que no sufran mis hermanos. Me di cuenta que él me llamó para alzar la voz por los que sufren y lloran. Aquella tarde salió de mi ser la siguiente oración: "Señor Dios, que tu espada corte mi alma en dos si es necesario, pero no me dejes caer en la indiferencia; no me dejes solo, guíame en este camino lleno de oscuridad, de dolor y de sufrimiento, porque tú eres amor y misericordia" y por fin logré entender a aquel vagabundo, tenía que actuar, ya no podía hacerme el ciego y sordo otra vez. Aquel día sentí que Dios tocó mi corazón con la punta de su espada. No sé por qué me llamó, pero me siento feliz de haberlo podido escuchar, me mostró la realidad tal y como es, no para llenarme de miedo sino para ser su soldado en esta lucha. Hoy oro para que ustedes, mis hermanos luchen a mi lado, por un mundo solidario, por un mundo diferente, por un mundo mejor. Para que el oprimido se libere y haya justicia, para que el que llora sea consolado, para que el huérfano y la viuda sean atendidos. A todos mis hermanos les pido, unámonos y hagamos de este mundo un lugar mejor, porque nadie lo hará si nosotros no tenemos el valor de atrevernos ahora.

Les pregunto, isomos conscientes que vivimos en un país en decadencia moral?, donde a pesar del crecimiento económico, los campesinos no tienen tierras, millones de familias carecen de techo, muchos trabajadores no tienen derechos y tantas personas están heridas en su dignidad. Muchos vemos sin mirar y oímos sin escuchar... No somos totalmente conscientes y muchas veces, me incluyo, no queremos darnos cuenta de que nuestro país está en problemas, y que la respuesta está en la solidaridad. Queremos hacernos los locos y dejar que todo siga su marcha, tal vez porque este sistema ahora no nos afecta directamente; pero no olvidemos que Dios espera nuestra ayuda al prójimo. Tenemos que darnos cuenta de una vez que necesitamos un cambio y este no se dará si primero no somos conscientes de que se necesita uno.

Quiero reflexionar con ustedes un poco más sobre el cambio que creo necesitamos. Actualmente sé que ustedes se han percatado que vivimos en un mundo controlado por el dinero, lo idolatramos y pensamos que es lo único que importa, cuando en realidad es solo una artimaña del diablo para generar conflictos, daños y caos entre los hombres. Estamos siendo engañados. Por ejemplo se dice que se ha disminuido la pobreza, pero ello no es suficiente, pues hay miles de personas que se mueren de hambre cada día, mientras que a muchos limeños les sobra el pan, lo he visto con mis propios ojos, les cuesta compartir un plato de comida y dárselo al que lo necesita. 
Vivimos engañándonos con la idea de que ese no es nuestro problema y por lo tanto no debemos hacer nada.

Hace algunas semanas, en la universidad, nos pidieron crear una idea para solucionar un problema actual en la sociedad. Lo que hicimos fue simple: identificamos problemas había en nuestra realidad, -lamentablemente sobraron-, luego necesitábamos buscarle una solución creativa y para ello decimos crear una máquina en donde ricos y pobres salgan beneficiados. ¿A qué quiero llegar con esto? Primero, este proyecto no solo buscaba acabar con el problema de los pobres, que es el hambre, la explotación, etc., sino también acabar con el gran problema que tienen muchas de las personas adineradas, el espiritual. Segundo, quiero hacerles entender de que no es difícil generar cambios, simplemente se necesita la voluntad y una buena actitud. No entraré en detalle con respecto al proyecto porque me desviaría del tema, pero lo que deben saber es que no es difícil mejorar nuestra sociedad si todos ponemos de nuestra parte.

No hay que buscar solo el beneficio propio, ni ser egoístas. El problema está en que una minoría, cada vez más reducida, cree beneficiarse con este sistema, pero les aseguro que no, porque las apariencias engañan y a pesar de que piensen tenerlo todo, dentro de ellos reina la insatisfacción, la angustia y la tristeza, frutos de la "Cultura de muerte" que hablaba San Juan Pablo II. Por eso no debemos permitir que el capital se convierta en un dios y dirija nuestro comportamiento. No le echemos la culpa a nuestros gobernantes, porque la culpa la tenemos todos al no pensar en nuestros hermanos que sufren de hambre y no tienen donde dormir.

Todos somos parte de un mismo país y como tal debemos procurar el bienestar total de este; no esperemos que un nuevo gobernante lo haga, no reneguemos de nuestro país, no le echemos la culpa al de a lado, ni dejemos que el dinero tutele todo el sistema socioeconómico, pues este solo arruina nuestra sociedad, condena al hermano convirtiéndolo en su esclavo, destruye la fraternidad logrando que nos enfrentemos interponiendo nuestros intereses. Entonces, todo aquel que esté sufriendo por causa de este sistema promueva creativamente alternativas, busquemos solucionar el problema con las "Tres T" trabajo, techo y tierra con el fin de construir un país mejor.

Recalco la frase "proceso de cambio" que en Bolivia emocionó al Papa Francisco, pues la considero muy interesante, y mucho más en nuestro contexto, donde creemos que con el cambio de presidente, todos los problemas sociales se van a solucionar de un día para otro, de manera radical como si fuera un acto de magia. Dejemos de pensar que nuestros representantes en el gobierno van a realizar un cambio, dejemos de pensar que si se impone una opción política o una estructura social 
gracias al nuevo gobierno vamos a solucionar todos estos problemas que tenemos en nuestra sociedad. Tal vez mejoren un poco, porque se han comprometido a ello, pero no existirá un verdadero cambio si este no viene acompañado de una sincera conversión de actitudes.

Por eso, no esperemos resultados inmediatos y tampoco le dejemos todo el trabajo a nuestros gobernantes, pues el "proceso de cambio" al que se refiere el Santo Padre, requiere esfuerzo y dedicación, desprendimiento y solidaridad como una base sólida para un cambio sostenido, entonces conscientes de ello, busquemos juntos dar paso a paso, para lograr el tan esperado cambio en la sociedad.

Otra pregunta me mantiene inquieto icómo cambiar los corazones? En la historia contada al principio, yo cambie por el dolor que sentí al ver a mis hermanos sufrir, por ponerme en el lugar de ellos. Por eso los invito a ponerse en el lugar del otro, a mirar el rostro de nuestros hermanos que sufren: el rostro del campesino amenazado, del trabajador excluido, de la familia sin techo, del joven desocupado, del niño explotado; ya que cuando miramos y pensamos en estos rostros, sufrimos por ver tanto dolor y nos conmovemos, porque solo mirando las heridas de nuestro hermano y tomándolas como propias, podremos sentir lo que sienten, podremos entender y cambiar nuestros corazones. Esto nos conmueve y nos mueve, impulsándonos a buscar al que sufre para caminar juntos, consolarlo y sanar sus heridas, esa es la clave para cambiar los corazones. Necesitamos poner en práctica esa Cultura de Encuentro, porque como dice el Santo Padre "ni las ideas ni los conceptos se aman, se aman a las personas" y de esta actitud surge la esperanza, que es lo único que necesitamos para no rendirnos y poner en marcha este proyecto transformacional.

Entonces, ¿Que tenemos que hacer? La primera tarea consiste en poner la economía al servicio de nuestra comunidad. Los hombres y la tierra no deben estar al servicio del dinero, esta no debe reinar, puesto que si dejamos que el dinero gobierne no solo destruirá la tierra como ya lo ha probado varias veces, si no que destruirá por completo al mismo hombre que habita en ella. Entonces repito la pregunta, ¿Qué tenemos que hacer? Primero no debemos dejar que la economía sea un mecanismo de acumulación, segundo tenemos que conseguir que esta economía sea distribuida adecuadamente entre todos de manera equitativa, no de manera igualitaria, -términos muy diferentes-. Tenemos que tener muy claro que el objetivo de esta no es solo asegurar la comida o garantizar el acceso a las Tres "T", el verdadero objetivo debe consistir en garantizar la dignidad de cada uno de nuestros hermanos. En conclusión, tenemos que alcanzar una economía justa, en donde se creen las condiciones para que cada niño pueda gozar de una infancia sin sufrimiento y carencias, una juventud en donde puedan desarrollarse los talentos de manera plena, una adultez libre de 
explotaciones en la que se respeten los derechos y por último se pueda acceder a una digna jubilación en la ancianidad. Esta economía que se busca no es utópica sino posible, el problema entonces es que el sistema actual tiene otros objetivos y por lo tanto atenta contra el proyecto divino de Jesús, que nos manda a distribuir de manera justa los frutos de la tierra. Lo que tenemos que hacer entonces es cambiar primero nuestros paradigmas, dejar de echarle la culpa a los que nos representan y cambiar nuestros corazones, con el fin de cambiar los objetivos de este sistema.

Quiero terminar diciendo que soy consciente que "algún día moriremos, pero los demás días no", por ello y los desafío en este reto, quiero que mi vida valga la pena ser vivida, no quiero irme de este mundo sin haber hecho nada en la realidad que me tocó vivir, quiero ser consciente que di todo lo que pude dar antes de morir.

\section{Bibliografía}

Viaje apostólico del Santo Padre Francisco a Ecuador, Bolivia y Paraguay (2, 2015, Santa Cruz de la Sierra, Bolivia). Participación en el II Encuentro Mundial de los Movimientos Populares. Santa Cruz de la Sierra, Bolivia, Librería Editrice Vaticana, 20I5. pp. 2-II 